\title{
Women's perspectives on termination service delivery in Vietnam: a cross-sectional survey in three provinces
}

This article was published in the following Dove Press journal:

International Journal of Women's Health

30 October 2014

Number of times this article has been viewed

\author{
Thoai D Ngo ${ }^{1,2}$ \\ Caroline Free' \\ Hoan T Le ${ }^{3}$ \\ Phil Edwards' \\ Kiet HT Pham ${ }^{4}$ \\ Yen BT Nguyen ${ }^{4}$ \\ Thang $\mathrm{H}$ Nguyen $^{5}$ \\ 'Faculty of Epidemiology and \\ Population Health, London School \\ of Hygiene and Tropical Medicine, \\ ${ }^{2}$ Research, Monitoring, and Evaluation \\ Team, Health System Department, \\ Marie Stopes International, London, \\ UK; ${ }^{3}$ Department of Environmental \\ Health, Hanoi Medical University, \\ ${ }^{4}$ Department of Health Economics, \\ Hanoi Medical University, ${ }^{5}$ Research \\ and Metrics Team, Marie Stopes \\ International Vietnam, Hanoi, Vietnam
}

Correspondence: Thoai D Ngo Research, Monitoring, and Evaluation Team, Health System Department, Marie Stopes International, I Conway Street, London WIT 6LP, UK

Tel +44 78 874I 4504

Fax +44 2070342372

Email thoai.ngo@mariestopes.org
Objective: To explore the perspectives of abortion service users regarding termination methods and abortion service delivery in Vietnam.

Materials and methods: Structured exit interviews were conducted between August and November 2011 with women who underwent termination of pregnancy at 62 public health facilities in Hanoi, Khanh Hoa, and Ho Chi Minh City in Vietnam. All women presenting for termination during the study period were recruited to participate in the study. Following their abortion, women were asked about their perspectives on abortion service delivery and attributes of medical abortion (MA) versus manual vacuum aspiration (MVA). Multiple logistic regression was used to assess the association between current method uptake and each attribute.

Results: A total of 1,233 women were included in the survey: 541 (43.9\%) from Hanoi, 163 (13.2\%) from Khanh Hoa, and 529 (42.9\%) from Ho Chi Minh: 23.1\% underwent MA; $78.9 \%$ reported that women should be given a choice between MA and MVA; and 77.6\% thought that abortion services were accessible. Among the 48\% who responded, 30.1\% thought that MA should be made available at primary/secondary health care facilities. Among women who had previously undergone both methods, women who reported that MA "feels more natural" (like a menstrual regulation/period) were more likely to choose MA for their current abortion (odds ratio 2.15, 95\% confidence interval 1.26-3.69).

Conclusion: MA uptake is significantly lower than MVA uptake. Further insights to women's perceptions of MA in Vietnam could help improve abortion service delivery in the country.

Keywords: Vietnam, medical abortion, misoprostol, mifepristone, manual vacuum aspiration, health service delivery

\section{Introduction}

Abortion was introduced in the early 1960s in Vietnam, ${ }^{1}$ where it is available upon request. Surgical termination using manual vacuum aspiration (MVA) exists at all public health administrative levels in the country, although medical abortion (MA), which was introduced in the country through a clinical study in $1992,{ }^{2}$ is only permitted at the central, provincial, and district levels for first-trimester termination and must be performed by obstetricians/gynecologists. ${ }^{2}$

There has been a relatively slow uptake of MA in Vietnam. The national percentage of abortions using MA was reported in 2002 to be $5 \%$, compared with $86 \%$ for MVA. ${ }^{3}$ MA uptake at public health facilities has also been found to vary by region. ${ }^{4}$ However, results of clinical trials on the effectiveness and acceptability of first-trimester MA among Vietnamese women indicate that MA offers an acceptable alternative to MVA. ${ }^{5-7}$ The reasons behind this low and varying uptake in Vietnam are largely unknown. 
The perceived safety and effectiveness of different abortion methods have been reported to influence women's selection of a method. ${ }^{8,9}$ Moreover, perceptions of the advantages and disadvantages of different abortion methods may also lead women to choose one method over another. Factors previously found to affect women's perceptions of MA and MVA include the lengths of the procedures, with some women reported to prefer the quicker MVA method, ${ }^{9,10}$ the lower pain level associated with MA, which causes some women to select MA over MVA, ${ }^{8,9}$ the number of clinic visits required, ${ }^{9,11}$ home use of misoprostol during MA, ${ }^{6,8,10,12-18}$ lack of surgical intervention with MA (positive factor), ${ }^{9,16,19-22}$ and costs associated with the abortion procedure (women paying out of pocket may select the cheaper option, which one study found to be MA). ${ }^{8}$ Another issue that may influence women in choosing one method over another is the degree of perceived control or autonomy that they have during the procedure. ${ }^{8}$ Women who regard MA as more "natural" than MVA may prefer MA. ${ }^{23}$

Understanding the relationship in Vietnam between women's perceptions of termination methods and their uptake is important to ensure that MA - a relatively new method - is made widely available and accessible to offer women choice. The last national assessment on MA provision in Vietnam was conducted in $2003,{ }^{2}$ and there has been no nationally representative quantitative survey. A cross-sectional exit-interview survey was therefore carried out to explore the perceptions of abortion service users about termination methods in Vietnam in relation to the uptake of MA versus MVA.

\section{Materials and methods}

A cross-sectional exit-interview survey was conducted among women receiving termination services at selected public health facilities in Hanoi municipality, Ho Chi Minh City (HCMC) municipality, and Khanh Hoa Province between August and December 2011. These locations were purposefully selected to represent geographical and cultural differences within the country (north, south, and central, respectively). The following public health facility levels were included: central specialist/general hospitals; provincial specialist/general hospitals or reproductive health centers (RHCs); and district hospitals/RHCs. All specialist hospitals/ RHCs were selected due to their small number; $50 \%$ of all nonspecialized facilities were selected using simple random sampling. In total, 62 health facilities were included.

All women presenting for termination services at these facilities and living in the province/municipality in which the health facility was located were eligible for inclusion. After their procedure and counseling session, women were invited to participate in a structured face-to-face exit interview, subject to written informed consent. Ethical approval for the study was granted from the institutional review boards at the London School of Hygiene and Tropical Medicine and Hanoi School of Public Health.

The interview questionnaire was developed in English, translated into Vietnamese, revised following a pilot, and back-translated into English. The questionnaire collected information on sociodemographic characteristics, reproductive and contraceptive history, understanding of service availability, perceived advantages and disadvantages for women of MA versus MVA, and perspectives on expansion of MA to primary and secondary health levels.

Statistical analyses were performed using Stata 11.1 (StataCorp, College Station, TX, USA). Due to the multistagesampling strategy in the study design, with respondents selected within facilities, all statistical analyses accounted for clustering using Stata survey commands. Because the proportion of sampled facilities differed according to the facility type, respondents attending general health facilities had half the probability of selection as those attending specialized facilities, and were thus given twice the weight of women attending specialized facilities in the analyses. Although this sample was not nationally representative, our study design ensured that it was representative of Hanoi, HCMC, and Khanh Hoa.

Descriptive analyses were carried out to show the distribution of sociodemographic and abortion-related characteristics and service-related factors stratified by regions (Hanoi, HCMC, and Khanh Hoa). The distribution of women's perspectives on termination service delivery was examined in a similar manner.

A subgroup analysis was conducted among women who had previously had both MVA and MA $(n=205)$ to assess women's perceptions of the attributes of MA and MVA (advantages and disadvantages of each). Logistic regression analyses were performed to assess the net effect of each attribute on the method uptake of that day's procedure (MVA or MA) among the 205 women who had experienced both methods prior to the current occasion. In a multiple logistic regression analysis, all attributes (advantages and disadvantages) were included in a model controlling for the following sociodemographic factors: age, region, education, number of children, and marital status.

\section{Results}

\section{Sociodemographic characteristics}

A total of 1,233 women were included in the survey: 541 (43.9\%) from Hanoi, 529 (42.9\%) from HCMC, 
and $163(13.2 \%)$ from Khanh Hoa. The survey response rate was $99.7 \%$; $76.9 \%$ of women had an MVA, and $23.1 \%$ had an MA. MA uptake was higher in Khanh Hoa (48.5\%) and HCMC (29.7\%) than in Hanoi (5.4\%). Compared with women in Hanoi and HCMC, women in Khanh Hoa were younger, and a higher proportion of them were childless, single, and still studying. Women in Hanoi were more educated, and a higher proportion were engaged in business/ government/office work than among clients in the other regions. They also appeared to have had significantly more repeat abortions (two or more abortions) $(41.0 \%$ ) than women in HCMC (28.0\%) and Khanh Hoa $(22.1 \%, P<0.001)$.

Women in HCMC paid significantly more for their abortion, with a mean of $₫ 667,000$ ( $\sim$ US\$33.35) compared with a mean of $\underline{d} 419,000$ in Hanoi and $₫$ d392,000 in Khanh Hoa $(P<0.001)$. A significantly greater proportion of women in HCMC reported paying more than expected (38\% versus $7 \%$ in the two other regions, $P<0.001$ ) (Table 1).

Among the 406 women who had had two or more abortions, $85.8 \%$ had MVA for their current procedure, while $14.2 \%$ underwent MA. The majority (81\%) of women who had MVA for their current abortion also had MVA for their first abortion. Among women who had an MA for their current procedure, $36 \%$ had the same procedure for their first abortion, and 30\% had both MA and MVA for their first abortion (MA followed by MVA where MA resulted in incomplete abortion). Table 1 compares the sociodemographic, abortion-related, and service-related characteristics of women included in the survey, by region.

\section{Perspectives on termination service delivery}

When asked whether women should be given a choice between MA and MVA, 78.9\% of study participants reported that women should be given a choice, $17.1 \%$ said they should not be given a choice, and the rest did not know or were unable to give an answer. Among the $48 \%$ of women who responded, $\sim 30.1 \%$ of women said that MA should be made available at primary and secondary health care facilities (commune health stations and district-level facilities, respectively).

Most women (77.6\%) stated that abortion services were accessible; a significantly higher proportion of women reported that abortion services were accessible in Hanoi (86\%) than in Khanh Hoa (76\%) and HCMC (71\%, $P<0.001)$. When asked which procedure was most accessible, 38.6\% thought MVA was more accessible, 29.2\% reported that MA was more accessible, and 19.0\% thought both were equally accessible. More than half of women in Hanoi (57\%) felt that MVA was most accessible, compared with only $24 \%$ in HCMC and $19 \%$ in Khanh Hoa. Data on women's perceptions of barriers to accessing abortion services in each of the three regions are presented in a separate paper (submitted for publication).

\section{Perceptions of the attributes of MA versus MVA}

Table 2 demonstrates the main factors in favor of MA or MVA cited by $\sim 16.6 \%(n=205)$ of the study population who had undergone both procedures prior to this occasion. The gray areas denote factors that were not asked about for a particular procedure, since they were not applicable to the specific method. Compared with MVA, a significantly higher proportion of women cited the following attributes as being positively associated with MA: less pain $(29.1 \%$ versus $46.7 \%, P=0.013)$, being natural $(12.8 \%$ versus $40.0 \%, P=0.001)$, and being affordable $(1.3 \%$ versus $8.3 \%$, $P=0.034)$. A significantly higher proportion of women cited that MA was associated with more adverse events/complications compared with MVA (31.1\% versus 6.4\%, $P=0.001)$.

Logistic regression analyses were performed to assess the net effect of each attribute on method uptake for the current procedure (MVA or MA) among the 205 women who had had both methods prior to this occasion. Unadjusted logistic regression showed that such attributes as having more complications (odds ratio [OR] 6.60, 95\% confidence interval [CI] 2.47-17.66), being less painful (OR 0.54, 95\% CI 0.30-0.96), and feeling more natural (OR 4.5, 95\% CI 2.13-9.67) were significantly associated with having had an MA for their current procedure (Table 3).

In a multivariate logistic regression analysis in which sociodemographic variables were controlled for, the only attribute cited by women that appeared to be significantly associated with the uptake of MA was that the method feels more natural (like a menstrual regulation/period) (OR 2.15, 95\% CI 1.26-3.69) (Table 3).

\section{Discussion}

In our study, almost a quarter (23.1\%) of women who underwent an abortion chose MA. Most women thought that they should be given a choice between MA and MVA (78.9\%), and most also stated that abortion services were accessible (77.6\%). Of the $48 \%$ of women who responded, less than a third $(30.1 \%)$ thought that MA should be made available at primary and secondary health care facilities. When women's perceptions of the attributes of MA and MVA were assessed 
Table I Sociodemographic, abortion-related, and service-related characteristics, by region

\begin{tabular}{|c|c|c|c|c|c|}
\hline \multirow[t]{2}{*}{ Characteristics } & \multirow{2}{*}{$\begin{array}{l}\text { Overall sample* } \\
\text { n (\%) }\end{array}$} & \multicolumn{3}{|c|}{ \% Distribution for each region } & \multirow[t]{2}{*}{$P$-value } \\
\hline & & Hanoi & Khanh Hoa & Ho Chi Minh & \\
\hline Total sample size & $\mathrm{n}=\mathrm{I}, 233(100)$ & $n=54 I$ & $n=163$ & $\mathrm{n}=529$ & \\
\hline \multicolumn{6}{|l|}{ Sociodemographics } \\
\hline \multicolumn{6}{|l|}{ Age-group (years) } \\
\hline $14-19$ & $81(6.6)$ & 4.6 & 11.2 & 6.5 & \\
\hline $20-24$ & $333(27.0)$ & 24.7 & 33.7 & 28.0 & \\
\hline $25-29$ & $296(24.0)$ & 26.0 & 18.1 & 23.2 & \\
\hline $30-34$ & $231(18.7)$ & 19.4 & 14.0 & 19.8 & \\
\hline $35+$ & $285(23.1)$ & 25.3 & 23.0 & 22.5 & \\
\hline Missing & $7(0.6)$ & - & - & - & $P=0.216$ \\
\hline \multicolumn{6}{|l|}{ Marital status } \\
\hline Single (never married) & $215(17.4)$ & 15.7 & 28.1 & 14.4 & \\
\hline Married & $959(77.8)$ & 83.4 & 64.6 & 79.8 & \\
\hline Divorced/separated & $7(0.6)$ & 0.3 & 0.0 & 1.3 & \\
\hline Living with partner & $37(3.0)$ & 0.6 & 7.3 & 4.5 & \\
\hline Missing & $15(1.2)$ & - & - & - & $P<0.09$ \\
\hline \multicolumn{6}{|l|}{ Educational attainment } \\
\hline None/primary & $93(7.5)$ & 3.6 & 8.4 & 13.0 & \\
\hline Secondary & $365(29.6)$ & 26.5 & 32.0 & 38.7 & \\
\hline High school/technical & $449(36.4)$ & 38.8 & 38.8 & 33.3 & \\
\hline College/university/postgraduate & $313(25.4)$ & 31.1 & 20.8 & 15.0 & \\
\hline Missing & $13(1.1)$ & - & - & - & $P<0.043$ \\
\hline \multicolumn{6}{|l|}{ Main occupation } \\
\hline Student & III (9.0) & 8.1 & 21.9 & 5.8 & \\
\hline Housewife & $215(17.4)$ & 12.2 & 20.2 & 22.6 & \\
\hline Farmer, manual, crafts & $217(17.6)$ & 24.3 & 26.4 & 11.2 & \\
\hline Businesswoman/owner, office work, government & $599(48.6)$ & 48.8 & 30.9 & 52.8 & \\
\hline Other & $82(6.7)$ & 6.5 & 0.6 & 7.6 & \\
\hline Missing & $9(0.7)$ & - & - & - & $P<0.0$ II \\
\hline \multicolumn{6}{|l|}{ Number of children } \\
\hline 0 & $393(31.9)$ & 25.9 & 41.6 & 32.1 & \\
\hline 1 & $314(25.5)$ & 23.5 & 21.9 & 26.6 & \\
\hline 2 & $442(35.8)$ & 43.7 & 33.2 & 32.5 & \\
\hline $3-8$ & $77(6.2)$ & 6.9 & 3.4 & 8.8 & \\
\hline Missing & $7(0.6)$ & - & - & - & $P<0.181$ \\
\hline \multicolumn{6}{|l|}{ Abortion-related characteristics } \\
\hline \multicolumn{6}{|l|}{ Number of abortions (including today) } \\
\hline One & $818(66.3)$ & 59.7 & 78.1 & 73.1 & \\
\hline Two or more & $406(32.9)$ & 40.4 & 21.9 & 26.9 & \\
\hline Missing & $9(0.7)$ & - & - & - & $P<0.016$ \\
\hline Was using contraception before this pregnancy & $600(48.7)$ & 42.5 & $50.0 \%$ & $56.5 \%$ & \\
\hline Missing & II (0.9) & - & - & - & $P<0.019$ \\
\hline \multicolumn{6}{|l|}{ Type of procedure } \\
\hline Surgical abortion & $937(76.0)$ & 94.4 & 45.9 & 76.9 & \\
\hline Medical abortion & $265(21.5)$ & 5.6 & 54.1 & 23.1 & \\
\hline Missing & $31(2.5)$ & - & - & - & $P<0.00$ I \\
\hline \multicolumn{6}{|l|}{ Service-related characteristics } \\
\hline \multicolumn{6}{|l|}{ Distance, home to clinic } \\
\hline Under 5 km & $393(31.9)$ & 37.8 & 45.5 & 22.2 & \\
\hline $5-9 \mathrm{~km}$ & $353(28.6)$ & 28.9 & 32.0 & 32.1 & \\
\hline $10-19 \mathrm{~km}$ & $295(23.9)$ & 19.9 & 15.2 & 30.8 & \\
\hline $20 \mathrm{~km}$ or more & $177(14.4)$ & 13.4 & 7.3 & 15.0 & \\
\hline Missing & $15(1.2)$ & - & - & - & $P<0.202$ \\
\hline \multicolumn{6}{|l|}{ Price paid for termination service $(\underline{d})^{\S}$} \\
\hline$<200,000$ & $132(10.7)$ & 26.1 & 4.0 & 2.4 & \\
\hline $200,000-399,000$ & $268(21.7)$ & 36.7 & 48.0 & 2.7 & \\
\hline
\end{tabular}


Table I (Continued)

\begin{tabular}{|c|c|c|c|c|c|}
\hline \multirow[t]{2}{*}{ Characteristics } & \multirow{2}{*}{$\begin{array}{l}\text { Overall sample* } \\
\text { n (\%) }\end{array}$} & \multicolumn{3}{|c|}{ \% Distribution for each region } & \multirow[t]{2}{*}{$P$-value } \\
\hline & & Hanoi & Khanh Hoa & Ho Chi Minh & \\
\hline $600,000-799,000$ & $257(20.8)$ & 7.0 & I.I & 35.4 & \\
\hline$>800,000$ & $163(13.3)$ & 6.7 & 0.6 & 24.1 & \\
\hline Missing & $35(2.8)$ & - & - & - & $P<0.001$ \\
\hline
\end{tabular}

Notes: *Overall sample did not use Stata survey commands; $₫ \underline{d} 20,000=$ US $\$$ I.

for their effect on the type of method chosen for their current abortion among a subgroup of women who had previously had both MVA and MA, multivariate analysis showed that women who reported that MA "feels more natural" (like a menstrual regulation/period) were more likely to choose MA for their current abortion.

The proportion of women undergoing MA in our study was higher than found in a 2002 study, in which MA uptake at Vietnamese public health facilities was $5 \%,{ }^{3}$ suggesting that MA uptake in Vietnam may be increasing.

Among those women in our study who had previously undergone both abortion methods, perceptions of a method's effectiveness were not associated with choosing an MA for their current abortion. A previous study in Vietnam showed that women choosing MA thought that surgical methods were more effective than MA. ${ }^{9}$ Studies in Latin America and the US previously found that most women opting for MA thought that MA was safer than surgical abortion. ${ }^{8,24}$ In our unadjusted analysis, more women thought that MA was less safe than MVA than vice versa. However, this factor did not emerge as

Table 2 Women's perceptions of method's attributes among those who had previously had both medical abortion (MA) and manual vacuum aspiration (MVA) $(n=205)$

\begin{tabular}{|c|c|c|c|}
\hline Attributes & $\begin{array}{l}\text { MVA } \\
\text { n (\%) }\end{array}$ & $\begin{array}{l}\text { MA } \\
n(\%)\end{array}$ & $P$-value \\
\hline Less effective (efficacy) & $5(6.4)$ & $13(10.8)$ & $P=0.290$ \\
\hline $\begin{array}{l}\text { Associated with more adverse } \\
\text { events/complications (safety) }\end{array}$ & $5(6.4)$ & $38(31.1)$ & $P=0.001$ \\
\hline $\begin{array}{l}\text { The procedure is shorter } \\
\text { (less time/fewer clinic visits) }\end{array}$ & $4(5.1)$ & $9(7.5)$ & $P=0.510$ \\
\hline Less painful & $23(29.1)$ & $56(46.7)$ & $P=0.013$ \\
\hline Can be done at home & - & $35(29)$ & - \\
\hline $\begin{array}{l}\text { Does not require surgical } \\
\text { intervention }\end{array}$ & - & $51(42.5)$ & - \\
\hline Affordable (costs less) & $\mathrm{I}(\mathrm{I} .3)$ & $10(8.3)$ & $P=0.034$ \\
\hline $\begin{array}{l}\text { More in control } \\
\text { (know what is happening) }\end{array}$ & $\mathrm{I}(\mathrm{I} .3)$ & $7(5.8)$ & $P=0.112$ \\
\hline $\begin{array}{l}\text { Feel more natural } \\
\text { (like a menstrual regulation/period) }\end{array}$ & $10(12.8)$ & $48(40.0)$ & $P=0.00 \mathrm{I}$ \\
\hline Private/confidential & $10(12.8)$ & $27(22.5)$ & $P=0.088$ \\
\hline Can have someone with me & $\mathrm{I}(\mathrm{I} .3)$ & $6(5.0)$ & $P=0.166$ \\
\hline
\end{tabular}

significant after multivariate analyses. Previous studies have not evaluated these factors within adjusted analyses.

In our study, procedure length and number of clinic visits were not associated with women choosing MA for their current procedure. In studies in Vietnam and the US in which women chose between MVA and MA, a larger proportion selected MVA because they considered it simpler and faster than MA. ${ }^{9,10}$ Women in the Vietnamese study who selected MVA also cited fewer clinic visits as the main driver behind their choice. ${ }^{9}$ Furthermore, an Ethiopian study found that significantly more women living in rural areas chose MVA over MA, explained as being to avoid repeat visits and travel time. ${ }^{11}$

In this survey, only $29 \%$ of those with previous experience of MA and MVA cited home use of misoprostol as an advantage. Studies in the US, Vietnam, and Tunisia have suggested that home use of misoprostol is as an advantage, due to the privacy and convenience that it affords, as well as the ability to have a family member close at hand to provide support. ${ }^{6,10,13-15}$ However, some studies have noted that women do not favor home-based MA when the abortion needs to be kept hidden from the rest of the household, when there is a lack of adequate facilities (toilet, running water, and menstrual pads), or when there is no medical professional readily available for advice. ${ }^{8,12,16,17}$ Findings from this survey and others imply that acceptability of home-based MA is based on the woman's circumstances.

In our study, in unadjusted analysis, a significantly higher proportion of women cited "less painful" as a positive attribute associated with MA over MVA. This finding is consistent with previous findings from Vietnam, ${ }^{9}$ Colombia, Ecuador, and Peru, where women chose MA because they thought it would be less painful than surgical methods or to avoid pain. ${ }^{8}$ Previous studies have suggested that some women choose MA because of fear of anesthesia or surgery. ${ }^{9,19-22}$ Approximately $40 \%$ of women in our study with previous experience of MA and MVA considered not having to undergo surgical procedures as an advantage of MA.

In our study, out-of-pocket expenses for MVA and MA were broadly similar, although women who 
Table 3 Odds ratios (ORs) and 95\% confidence intervals (Cls) from unadjusted and adjusted analyses to identify women's perceptions associated with having had a medical abortion (MA) $(n=205)$

\begin{tabular}{|c|c|c|c|}
\hline Method attributes & $\begin{array}{l}\text { Unadjusted } \\
\text { ORs of MA } \\
(95 \% \mathrm{Cl})\end{array}$ & $\begin{array}{l}\text { Adjusted } \\
\text { ORs of MA* } \\
(95 \% \mathrm{Cl})\end{array}$ & $\begin{array}{l}P \text {-values for } \\
\text { adjusted ORs }\end{array}$ \\
\hline Less effective (efficacy) & $1.77(0.61-5.19)$ & $1.95(0.49-7.74)$ & $P=0.269$ \\
\hline $\begin{array}{l}\text { Associated with more adverse } \\
\text { events/complications (safety) }\end{array}$ & $6.60(2.47-17.66)$ & $2.28(0.34-15.36)$ & $P=0.316$ \\
\hline $\begin{array}{l}\text { The procedure is shorter } \\
\text { (less time/fewer clinic visits) }\end{array}$ & $1.50(0.45-5.05)$ & $1.29(0.19-8.98)$ & $P=0.464$ \\
\hline Less painful & $0.54(0.30-0.96)$ & $0.88(0.3 \mathrm{I}-2.56)$ & $P=0.778$ \\
\hline Can be done at home & - & - & - \\
\hline Does not require surgical intervention & - & - & - \\
\hline Costs less (affordability) & $7.0(0.88-55.82)$ & $0.75(0.17-3.24)$ & $P=0.637$ \\
\hline More in control (know what is happening) & $4.77(0.58-39.55)$ & $1.97(0.32-12.2)$ & $P=0.382$ \\
\hline $\begin{array}{l}\text { Feels more natural } \\
\text { (like a menstrual regulation/period) }\end{array}$ & $4.5(2.13-9.67)$ & $2.15(1.26-3.69)$ & $P=0.014$ \\
\hline More private/confidential & $1.97(0.90-4.35)$ & $0.56(0.04-7.88)$ & $P=0.595$ \\
\hline Can have someone with me & $4.05(0.48-34.33)$ & $1.13(0.36-3.54)$ & $P=0.787$ \\
\hline
\end{tabular}

Note: *In a multiple logistic regression analysis, all attributes (advantages and disadvantages) were included in a model controlling for the following sociodemographic factors: age, region, education, number of children, and marital status.

underwent MA thought that it was more affordable than MVA. However, affordability did not appear to be an important factor influencing method choice. A previous study in Latin America suggested that women chose MA because it was often cheaper than surgical abortion. ${ }^{8}$ However, this study evaluated the misoprostol-only regimen, which is cheaper than the mifepristone + misoprostol regimen.

We found that the perception of being in control was not associated with choosing MA. This is dissimilar to findings from qualitative studies in Latin America, in which women stated preferring MA to MVA as they had more control over the process and its success or failure. ${ }^{8}$

Our finding that a woman's perception of MA as being "more natural" was associated with choosing an MA is consistent with findings from the US, Vietnam, and Latin America. ${ }^{2,8,23}$ Studies reported that women considered MA to be like having a period ${ }^{23}$ and less likely to interrupt women's daily lives. $^{2}$

Our study represents the largest cross-sectional quantitative survey among abortion-seeking women to have been conducted in Vietnam. However, due to its cross-sectional nature and use of self-reported measures, our study possesses certain limitations. The measure concerning women's attitudes toward whether MA should be made available at primary and secondary health facilities had a high missing value $(\sim 50 \%)$, indicating that women were not familiar with the concept of health service expansion, which places the validity of this measure under question. However, there is no gold standard for measuring such indicators, as these have not been explored in previous studies. Since women who chose an MA for their current abortion were interviewed subsequently to mifepristone administration, it was not possible to fully assess their experience of the MA process, as the procedure is not complete until after the administration of misoprostol. Therefore, the analysis of women's perceptions of each method's attributes was limited to a subgroup of 205 women who reported that they had previously had both surgical abortions and MAs. This allowed for a more accurate assessment of women's perceptions. Face validity was used prior to full implementation of the study. Our findings can only be generalized to Vietnamese settings, since abortion service provision is dependent on national policies and cultural norms.

While the uptake of MA in Vietnam seems to have increased compared with figures reported in 2002, MA uptake is significantly lower than that of MVA and substantially lower than in other settings. Women's perceptions of the safety and effectiveness of MA in Vietnam do not appear to influence their uptake of MA, and while most potential advantages of MA over MVA did not appear to influence MA uptake among Vietnamese women in our study, the perception of MA as being more natural than MVA appears an important exception. It is important to fully understand women's perspectives regarding the expansion of MA to primary and secondary health facilities. Qualitative studies should further investigate women's perceptions in this area to ensure that expansion efforts meet women's needs. To ensure that MA can be expanded to rural areas where primary health 
care facilities are located, future research should evaluate the operational constraints relating to MA implementation in rural settings, and safety, effectiveness, and acceptability outcomes. About a third of women in this study had had repeat abortions. With the advent of MA, it is also important to evaluate various interventions, such as mobile health as follow-up care or vouchers as demand-side financing mechanisms to improve postabortion family-planning uptake.

\section{Acknowledgments}

The authors wish to thank the Departments of Health in Hanoi, Khanh Hoa, and Ho Chi Minh City for their support with this study. Marie Stopes International provided funding for the study.

\section{Disclosure}

The authors report no conflicts of interest in this work.

\section{References}

1. Sedgh G, Henshaw SK, Singh S, Bankole A, Drescher J. Legal abortion worldwide: incidence and recent trends. Perspect Sex Reprod Health. 2007;39:216-225.

2. Ganatra B, Bygdeman M, Phan BT, Nguyen DV, Vu ML. From research to reality: the challenges of introducing medical abortion into service delivery in Vietnam. Reprod Health Matters. 2004;12:105-113.

3. Nguyen M. Vietnam National Abortion Survey. Hanoi: Committee for Population, Family and Children; 2002.

4. Nha VQ, Le TP, Ngo VQ, Nguyen QC. Medical Abortion in Vietnam: Policy and the Situation of Service Provision in Private and Public Health Facilities in Ha Noi, Da Nang, and HCMC. Hanoi: Population Council; 2008.

5. Elul B, Hajri S, Ngoc NN, et al. Can women in less-developed countries use a simplified medical abortion regimen? Lancet. 2001;357:1402-1405.

6. Ngoc NT, Nhan VQ, Blum J, Mai TT, Durocher JM, Winikoff B. Is home-based administration of prostaglandin safe and feasible for medical abortion? Results from a multisite study in Vietnam. BJOG. 2004;111:814-819.

7. Nguyen TN, Blum J, Durocher J, Quan TT, Winikoff B. A randomized controlled study comparing 600 versus $1,200 \mu \mathrm{g}$ oral misoprostol for medical management of incomplete abortion. Contraception. $2005 ; 72: 438-442$

8. Lafaurie MM, Grossman D, Troncoso E, Billings D, Chávez S. Women's perspectives on medical abortion in Mexico, Colombia, Ecuador and Peru: a qualitative study. Reprod Health Matters. 2005;13:75-83.
9. Ngoc NT, Winikoff B, Clark S, et al. Safety, efficacy and acceptability of mifepristone-misoprostol medical abortion in Vietnam. Int Fam Plan Perspect. 1999;25:10-44.

10. Shochet T, Trussell J. Determinants of demand: method selection and provider preference among US women seeking abortion services. Contraception. 2008;77:397-404.

11. Woldetsadik MA, Sendekie TY, White MT, Zegeye DT. Client preferences and acceptability for medical abortion and MVA as early pregnancy termination method in northwest Ethiopia. Reprod Health 2011;8:19.

12. Gresh A, Maharaj P. A qualitative assessment of the acceptability and potential demand for medical abortion among university students in Durban, South Africa. Eur J Contracept Reprod Health Care. 2011;16:67-75.

13. Hajri S, Blum J, Gueddana N, et al. Expanding medical abortion in Tunisia: women's experiences from a multi-site expansion study. Contraception. 2004;70:487-491.

14. Elul B, Pearlman E, Sorhaindo A, Simonds W, Westhoff C. In-depth interviews with medical abortion clients: thoughts on the method and home administration of misoprostol. J Am Med Womens Assoc. 2000;55:169-172.

15. Fielding SL, Edmunds E, Schaff EA. Having an abortion using mifepristone and home misoprostol: a qualitative analysis of women's experiences. Perspect Sex Reprod Health. 2002;34:34-40.

16. Berer M. Medical abortion: issues of choice and acceptability. Reprod Health Matters. 2005;13:25-34

17. Bennett LR. Single women's experiences of premarital pregnancy and induced abortion in Lombok, Eastern Indonesia. Reprod Health Matters. 2001;9:37-43.

18. Hamoda H, Critchley HO, Paterson K, Guthrie K, Rodger M, Penney GC. The acceptability of home medical abortion to women in UK settings. BJOG. 2005; 112:781-785.

19. Henshaw RC, Naji SA, Russell IT, Templeton AA. Comparison of medical abortion with surgical vacuum aspiration: women's preferences and acceptability of treatment. BMJ. 1993;307:714-717.

20. Winikoff B, Sivin I, Coyaji KJ, et al. Safety, efficacy and acceptability of medical abortion in China, Cuba and India: a comparative trial of mifepristone-misoprostol versus surgical abortion. Am J Obstet Gynecol. 1997;176:431-437.

21. Creinin MD, Burke AE. Methotrexate and misoprostol for early abortion: a multicenter trial. Acceptability. Contraception. 1996;54:19-22.

22. Winikoff B, Ellertson C, Elul B, Sivin I. Acceptability and feasibility of early pregnancy termination by mifepristone-misoprostol. Results of a large multicenter trial in the United States. Arch Fam Med. 1998;7:360-366.

23. Simonds W. Abortion at Work: Ideology and Practice in a Feminist Clinic. New Brunswick (NJ): Rutgers University Press; 1996.

24. Clark S, Ellertson C, Winikoff B. Is medical abortion acceptable to all American women: the impact of sociodemographic characteristics on the acceptability of mifepristone-misoprostol abortion. J Am Med Womens Assoc. 2000;53:177-182.
International Journal of Women's Health

\section{Publish your work in this journal}

The International Journal of Women's Health is an international, peerreviewed open-access journal publishing original research, reports, editorials, reviews and commentaries on all aspects of women's healthcare including gynecology, obstetrics, and breast cancer. The manuscript management system is completely online and includes

\section{Dovepress}

a very quick and fair peer-review system, which is all easy to use. Visit http://www.dovepress.com/testimonials.php to read real quotes from published authors. 